\title{
Prediction of residual stress using explicit finite element method
}

\author{
W.A. Siswanto ${ }^{1}$, M.Nagentrau ${ }^{1 *}$ and A.L. Mohd Tobi ${ }^{1}$ \\ ${ }^{1}$ Faculty of Mechanical and Manufacturing Engineering, \\ Universiti Tun Hussein Onn Malaysia, Batu Pahat, Malaysia \\ *Email: nagentrau.rau17@yahoo.com \\ Phone: +60174039241; Fax: +6074536080
}

\begin{abstract}
This paper presents the residual stress behaviour under various values of friction coefficients and scratching displacement amplitudes. The investigation is based on numerical solution using explicit finite element method in quasi-static condition. Two different aeroengine materials, i.e. Super CMV (Cr-Mo-V) and Titanium alloys (Ti-6Al$4 \mathrm{~V}$ ), are examined. The usage of FEM analysis in plate under normal contact is validated with Hertzian theoretical solution in terms of contact pressure distributions. The residual stress distributions along with normal and shear stresses on elastic and plastic regimes of the materials are studied for a simple cylinder-on-flat contact configuration model subjected to normal loading, scratching and followed by unloading. The investigated friction coefficients are 0.3, 0.6 and 0.9, while scratching displacement amplitudes are $0.05 \mathrm{~mm}, 0.10 \mathrm{~mm}$ and $0.20 \mathrm{~mm}$ respectively. It is found that friction coefficient of 0.6 results in higher residual stress for both materials. Meanwhile, the predicted residual stress is proportional to the scratching displacement amplitude, higher displacement amplitude, resulting in higher residual stress. It is found that less residual stress is predicted on Super CMV material compared to Ti-6Al-4V material because of its high yield stress and ultimate strength. Super CMV material with friction coefficient of 0.3 and scratching displacement amplitude of $0.10 \mathrm{~mm}$ is recommended to be used in contact engineering applications due to its minimum possibility of fatigue.
\end{abstract}

Keywords: Friction coefficient; sliding amplitude; Cylinder-on-flat; Ti-6Al-4V; Super CMV

\section{INTRODUCTION}

Residual stress in contact mechanics is one of the crucial and interesting subjects in fatigue life, part distortion and corrosion resistance are influenced by residual stress, especially in engineering applications such as automotive, machining, nuclear power plant and aeroengine field [1]. Residual stress can be defined as the stress that remains in a body after the removal of the original source of the stress. The influences of the residual stress might be beneficial or detrimental depending on the magnitude and distribution of the stress [2]. Fatigue life of material is influenced by residual stress where a number of studies demonstrated the effect of residual stress in prediction of fatigue life [3-6]. Advancement in numerical residual stress prediction approach is essential as experimental method has numerous limitations such as intensive labour, time consuming, limited sample size, shape, accuracy of measurement, machine capacity and operator skill $[1,3]$. So, a wide range of engineering problems is solved using finite element approach [7-10]. It is necessary to study the effect of friction coefficient and scratching or sliding 
displacement amplitude on the residual stress. Super CMV (Cr-Mo-V) and Titanium alloys (Ti-6Al-4V) materials have been examined by a number of researchers because of their wide range of applications in aeroengines and gas turbines [11-18]. A number of studies demonstrated the response of residual stress influenced by the coefficient of friction and scratching or sliding [19, 20]. Proper numerical model and contact formulation must be employed to signify the contact residual stress behaviour using finite element simulations [21, 22]. A stress-based finite element model of friction behaviour effect on residual stresses is presented by Yang and Liu [3], where significant role of residual stress in determining the fatigue life is reported. Meanwhile, Liu and Guo [23] demonstrated the sensitivity of residual stress prediction depending on friction coefficient in the study of finite element analysis of the effect of sequential cuts and tool-chip friction on residual stresses in a machined layer. In addition, the obtained residual stress in the proposed semi-analytical method for rolling and sliding contact by Foletti and Desimone [24] gives good agreement with finite element method considering non-linear kinematic hardening model. The study of directional development of residual stress and surface fatigue during sliding contact was investigated by Linz et al. [25], which shows that transversal residual stress increases to $250-300 \mathrm{MPa}$ after the $10^{\text {th }}$ cycle and remains constant for any further increment in sliding cycles. However, to the best of the author's knowledge, far too little attention has been paid to compare the friction coefficient and displacement amplitude on residual stress simulation responses on elastic-plastic halfspace of advanced alloys, including aeroengine materials such as Ti-6Al-4V and Super CMV alloys.

In this paper, von Mises residual stress along with normal and shear stress distributions using various values of friction coefficients and scratching displacement amplitudes for a cylinder-on-flat contact configuration model under quasi-static condition are predicted for Super CMV and Ti-6Al-4V alloys using explicit finite element approach. The contact pressure distributions for both material models is verified and compared to Hertzian contact theoretical solution. The effect of friction coefficient and scratching displacement amplitude on residual stress is compared and studied.

\section{FE MODELLING APPROACH}

A commercial FE software ABAQUS/Explicit is employed to analyse the residual stress along with normal and shear stress distributions in quasi-static condition as explicit approach is suitable for complex contact problems with material degradation and failure [26]. At first glance, it appears that the implicit solver would be the appropriate choice for modelling highly nonlinear static problems. However, explicit solvers are more efficient for this class of problems as explicit finite element method is suitable for solving wave propagation analysis and high-speed (short duration) dynamics, drop tests and crash analyses of structural members, large, nonlinear, quasi-static analyses, deep drawing, blow molding, and assembly simulations, highly discontinuous post buckling and collapse simulations, structural acoustics and coupled temperature-displacement. A cylinder-on-flat contact configuration model based on earlier experimental studies [13, $14]$ is employed throughout the simulation. Figure 1 illustrates the corresponding 2D Finite element model consisting of rectangle as a substrate with dimension of $12 \times 6 \mathrm{~mm}$ and half-circle as an indenter with $6 \mathrm{~mm}$ radius, $\mathrm{R}$. Two different aeroengine materials, i.e. high strength steel Super CMV (Cr-Mo-V) and light weight alloy Ti-6Al-4V, are examined in this study.

As explicit algorithm requires density, the density values, $\rho$ of $7.94 \times 10^{-9}$ 
tonne $/ \mathrm{mm}^{3}$ and $4.43 \times 10^{-9}$ tonne $/ \mathrm{mm}^{3}$ are taken for Super CMV and Ti-6Al-4V respectively. The modulus of elasticity, E of $200 \mathrm{GPa}$ and $115 \mathrm{GPa}$ assigned for Super CMV and Ti-6Al-4V. Meanwhile, similar Poisson's ratio, $v$ of 0.3 , is employed for both materials $[13,27]$. The plasticity data for Super CMV and Ti-6Al-4V material is obtained from the study presented by Leen et al. [28] and Benedetti \& Fontanari [29] as shown in Table 1.

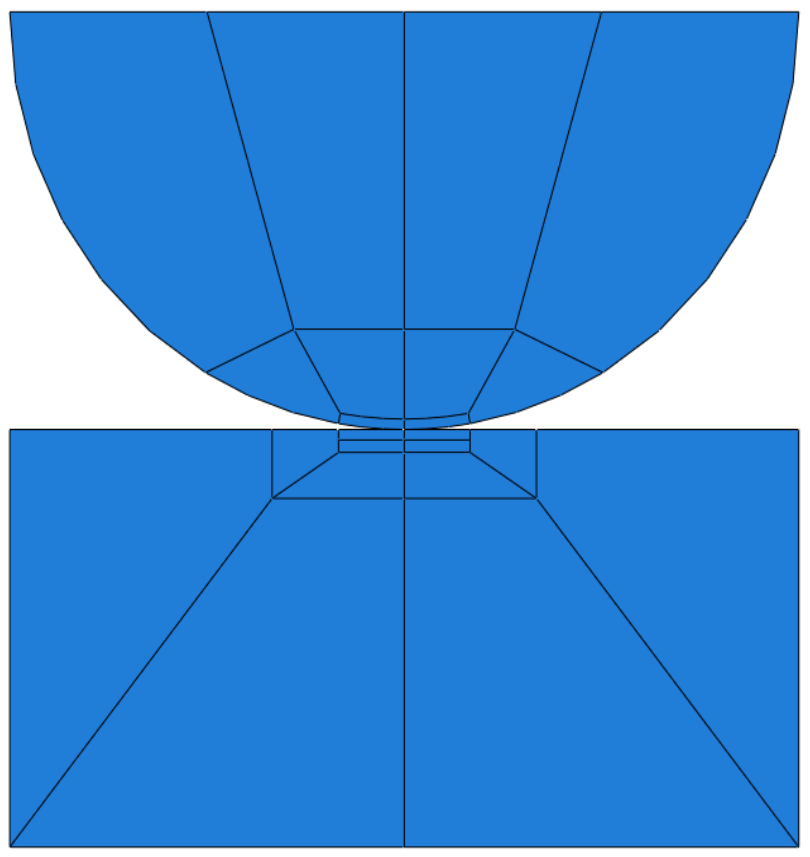

Figure 1. Partitioned 2D Finite element model.

Table 1. Plastic properties of Super CMV and Ti-6Al-4V [28, 29].

\begin{tabular}{cccc}
\hline $\begin{array}{c}\text { Yield stress, MPa } \\
\text { (Super CMV) }\end{array}$ & $\begin{array}{c}\text { Plastic strain } \\
\text { (Super CMV) }\end{array}$ & $\begin{array}{c}\text { Yield stress, MPa } \\
\text { (Ti-6Al-4V) }\end{array}$ & $\begin{array}{c}\text { Plastic strain } \\
\text { (Ti-6Al-4V) }\end{array}$ \\
\hline 1240.36 & 0 & 744.57 & 0 \\
1419.01 & 0.000401 & 811.43 & 0.001539 \\
1551.73 & 0.001244 & 844.00 & 0.003049 \\
1648.71 & 0.004111 & 857.71 & 0.004025 \\
1674.23 & 0.007506 & 875.71 & 0.006038 \\
1623.19 & 0.010690 & 885.14 & 0.008021 \\
1561.94 & 0.012524 & 897.14 & 0.010034 \\
1505.79 & 0.013958 & 907.43 & 0.012017 \\
\hline
\end{tabular}

The plane strain, explicit linear quadrilateral elements were used at the contact region throughout the simulation as high reliability contact performance can be achieved, especially for frictional contact problems. The size of the mesh assigned at the contact region is about $5 \mu \mathrm{m}$, while edge seeding is practiced for mesh transition from fine to course. A study on mesh sensitivity has been carried out on the influence of element size in the contact region where the size of the element varied from $10 \mu \mathrm{m}$ to $1 \mu \mathrm{m}$. In addition, 
$5 \mu \mathrm{m}$ mesh size is considered appropriate for this study as the additional mesh refinement gives a negligible effect on predicted stress distributions, but increases the computational time. Mesh module is refined at the contact region in order to obtain better residual stress prediction with reasonable CPU times as shown in Figure 2. The cylinder (indenter) and flat surface (substrate) are assigned as master and slave surfaces respectively. The surface-to-surface contact technique with finite sliding formulation is used for contact interactions. In addition, Penalty friction formulation with friction coefficient, $\mu=0.3$ is employed. The side and bottom surfaces of the flat plate are fully constrained from any translation and rotation motions.

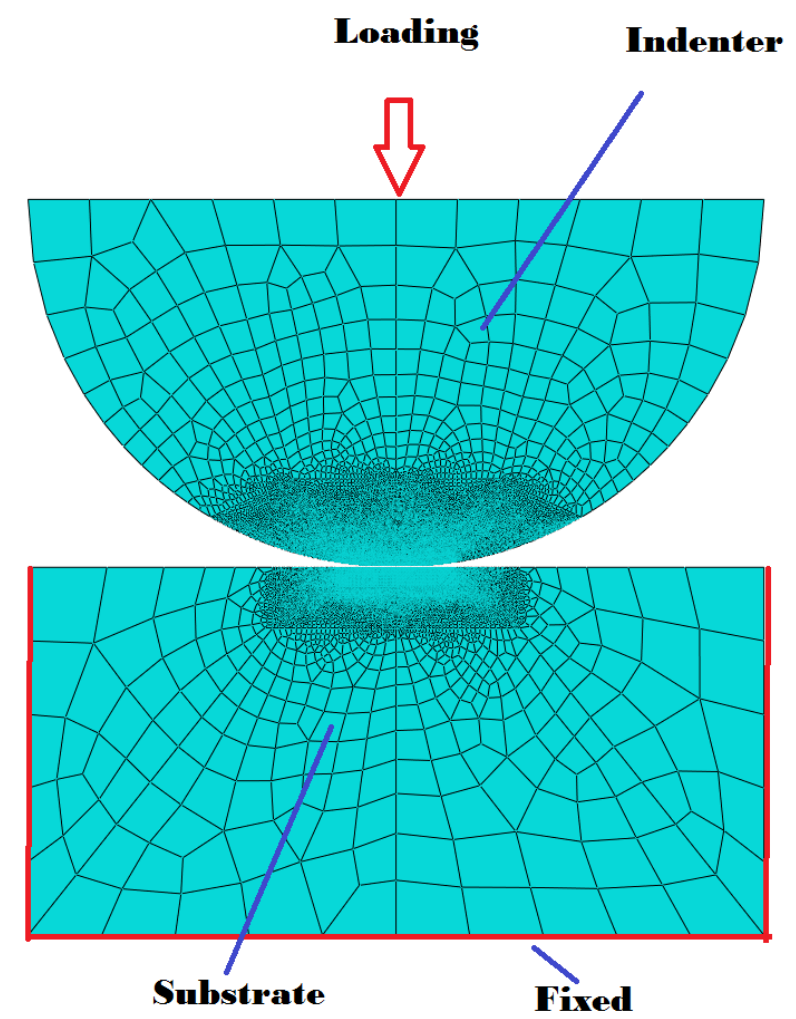

Figure 2. 2D Finite element mesh module.

Dynamic explicit steps with time period of $0.00015 \mathrm{~s}$ are assigned. The calculated kinetic energy term should remain below $5 \%$ of the total internal energy of the system for a quasi-static deformation process and this condition is achieved when $t=0.00015$. The simulation is performed with three steps, i.e. loading, scratching and unloading. A concentrated force, $P$ of $1000 \mathrm{~N} / \mathrm{mm}$ applied at the indenter during loading throughout the analysis. Besides that, a displacement amplitude, $\delta$ of $0.1 \mathrm{~mm}$ is applied during scratching. A smooth step function is used to ramp up the loading and displacement progressively from zero to its maximum amplitude as shown in Table 2 to avoid undesired sudden dynamic effect. The Equation's type constraint is used to make sure the indenter moves concurrently with the point load. The friction coefficient of $0.3,0.6$ and 0.9 , while scratching displacement amplitudes of $0.05 \mathrm{~mm}, 0.10 \mathrm{~mm}$ and $0.20 \mathrm{~mm}$ applied in the FE simulation to study the influence on residual stress along with normal and shear stress distributions. The FE model is validated with Hertzian theoretical solution by verifying the contact pressure distributions. 
Table 2. Smooth step amplitude table

\begin{tabular}{cc}
\hline Time, $\mathrm{s}$ & Load amplification factor \\
\hline 0 & 0 \\
0.00015 & 1 \\
\hline
\end{tabular}

\section{RESULTS AND DISCUSSION}

The von Mises residual stress along with normal and shear stress distributions are predicted using different friction coefficients and scratching displacements amplitude using explicit finite element approach. Super CMV and Ti-6Al-4V materials contact conditions are examined. The contact pressure distributions are taken from the surface of the substrate whereas von Mises stress, residual stress, normal stress and shear stress are taken from the specific element at the subsurface of the substrate.

\section{Validation of Contact Variables}

Figure 3 shows FE predicted contact pressure distributions for Super CMV and Ti-6Al4V compared to Hertzian theoretical solution. The trend of the graph for both materials shows that the maximum contact pressure occurred at the center of the contact region. Based on Hertzian contact theoretical solution, $1707.315 \mathrm{MPa}$ of maximum contact pressure, po and $0.1865 \mathrm{~mm}$ of contact half-width length, $a$ calculated for Super CMV while, $1294.636 \mathrm{MPa}$ of maximum contact pressure, po and $0.2459 \mathrm{~mm}$ of contact halfwidth length, $a$ calculated for Ti-6Al-4V. The FE predicted maximum contact pressure, po for Super CMV and Ti-6Al-4V are 1704.54 MPa and 1286.24 MPa, whereas 0.195 $\mathrm{mm}$ and $0.255 \mathrm{~mm}$ of contact half-width length, $a$ is obtained respectively. The predicted contact variables give good agreement with Hertzian theoretical solution as the percentage error less than $5 \%$ is achieved, as shown in Table 3.

Table 3. Contact variables results and percentage error

\begin{tabular}{lcc}
\hline \multicolumn{1}{c}{ Material } & Super CMV & Ti-6Al-4V \\
\hline Maximum Contact pressure, MPa (HERTZ) & 1707.315 & 1294.636 \\
Maximum Contact pressure, MPa [30] & 1704.540 & 1286.240 \\
\% error & 0.163 & 0.649 \\
Contact half-width length, mm (HERTZ) & 0.187 & 0.246 \\
Contact half-width length, mm [30] & 0.195 & 0.255 \\
\% error & 4.278 & 3.659 \\
\hline
\end{tabular}

The maximum contact pressure, po, and half- width contact length, $a$, display good agreement with Hertzian theoretical solution with lower percentage errors for both materials. In addition, the maximum contact pressure occurred at the centre of the contact region as the stress intensity is higher at the contact point during loading process [31]. The higher contact pressure occurs on Super CMV compared to Ti-6Al-4V because of its high strength. Besides that, the contact half-width length, $a$ of Ti-6Al-4V higher than Super CMV for same amount of loading as Super CMV has higher hardening curve of the material compared to that of Ti-6Al-4V alloy. In addition, Super CMV material has higher elastic modulus and ultimate strength where it can withstand higher loads 
compared to Ti-6Al-4V. The percentage errors for maximum contact pressure and contact half-width length are due to the elastic half-space assumption employed in the Hertzian contact theoretical solution.

(a)

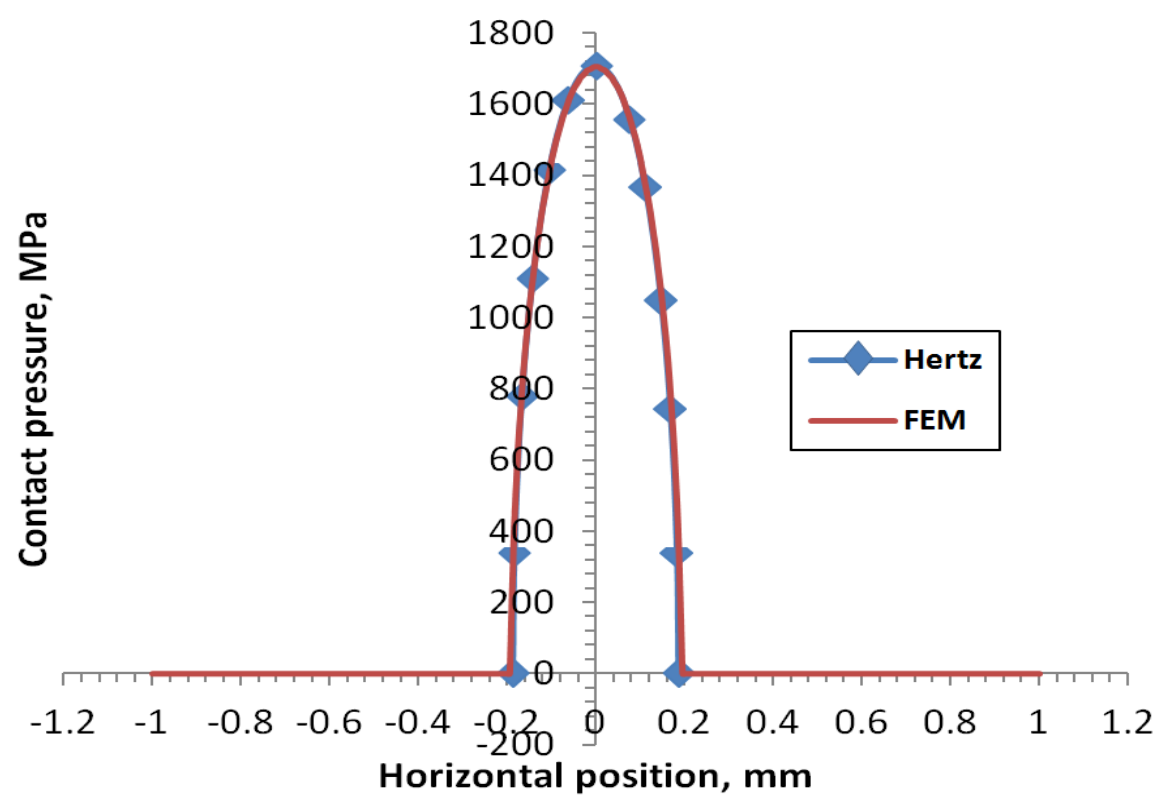

(b)

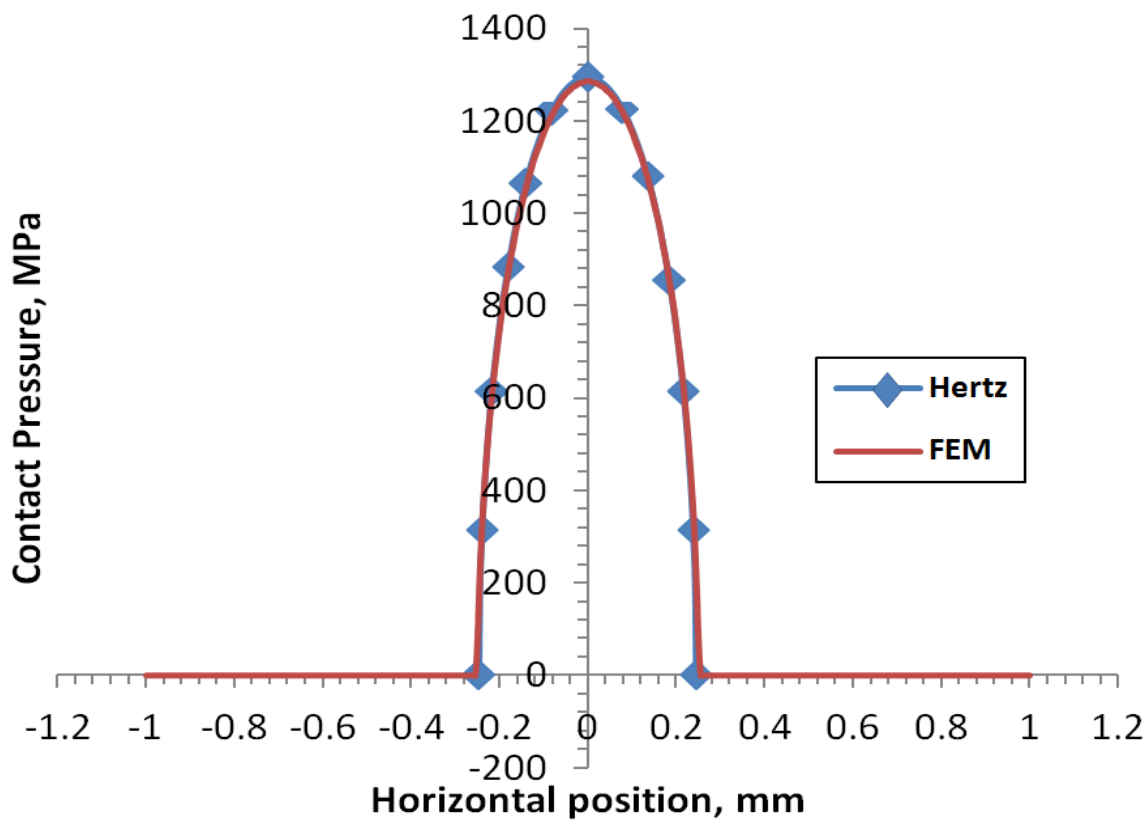

Figure 3. Contact pressure and contact half-width length comparison between FEM analysis and Hertzian contact theoretical solution for (a) Super CMV and (b) Ti-6Al$4 \mathrm{~V}$. 


\section{Influence of Friction Coefficient and Displacement Amplitude on Normal Stress Distributions}

Figure 4 illustrates normal stress history using different coefficients of frictions for Super $\mathrm{CMV}$ and Ti-6Al-4V materials. The graph shows a trend where negative normal stress is recorded as the force acts downwards in $-\mathrm{y}$ direction normal to the substrate. The normal stress acting on Super CMV is higher than Ti-6Al-4V. The normal stress increases during loading for all cases, whereas the effect of friction coefficient obviously can be seen during scratching for both materials. The higher coefficient of friction reduces the normal stress, where lower normal stress is noted for 0.9 friction coefficient compared to 0.6 and 0.3 , especially during scratching. The normal stress of substrate is relaxed after the removal of load for all conditions.

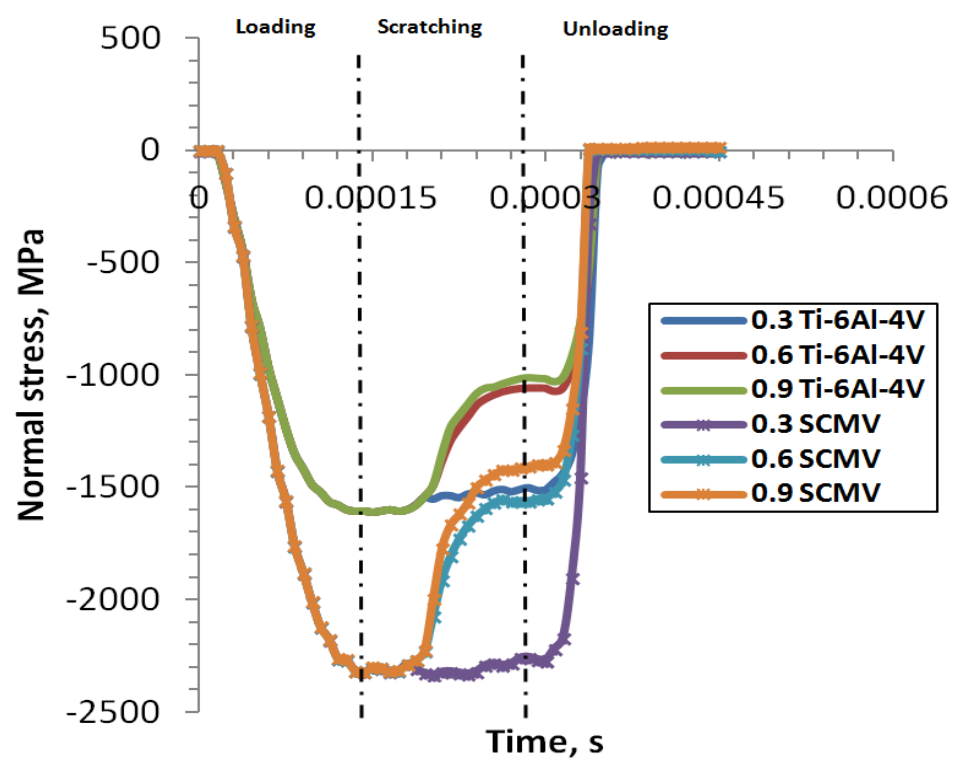

Figure 4. The normal stress history for different friction coefficients.

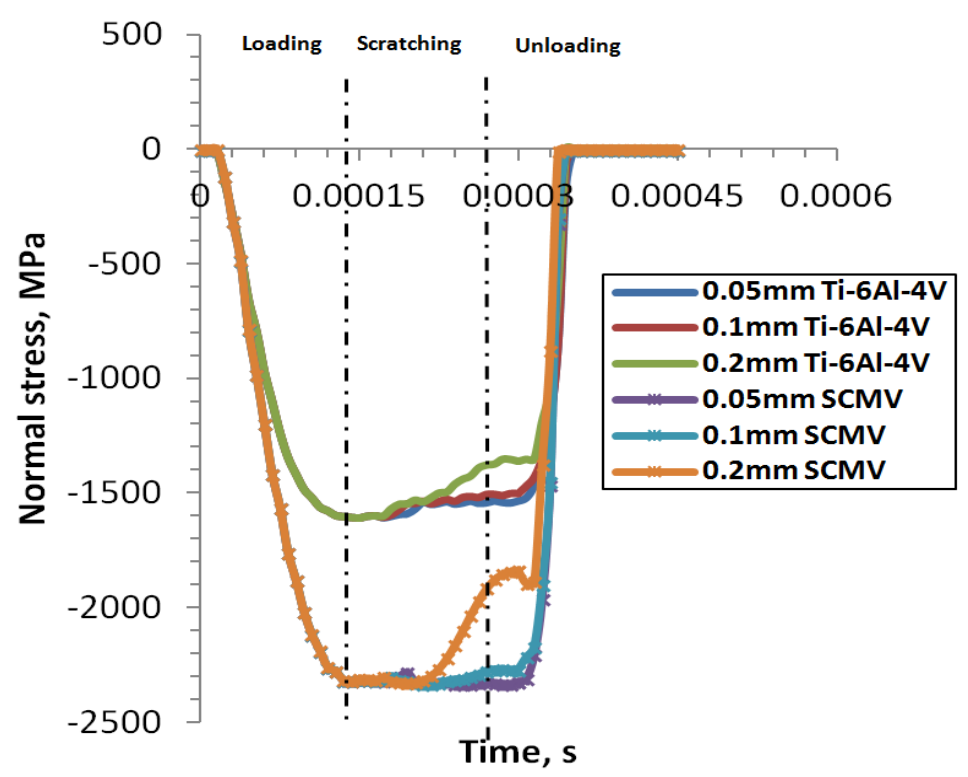

Figure 5. The normal stress history for different displacement amplitudes. 
Figure 5 illustrates normal stress history using different scratching displacement amplitudes for Super CMV and Ti-6Al-4V materials. The trend of the graph shows that negative normal stress is noted as the load acts downwards in $-\mathrm{y}$ direction normal to the surface of the substrate. In addition, the normal stress acts on Super CMV is greater compared with Ti-6Al-4V. The normal stress rises during loading for all the conditions, whereas the effect of displacement amplitude is noticeable during scratching for both materials. The higher displacement amplitude reduces the normal stress, as lower normal stress is predicted for displacement of $0.2 \mathrm{~mm}$ compared to $0.1 \mathrm{~mm}$ and $0.05 \mathrm{~mm}$, mainly during scratching. The normal stress of the substrate is gradually reduced after the unloading for all the displacement conditions. The effect of friction coefficient and scratching displacement amplitude is significant in normal stress graphs. The compressive stress acting on the sub surface's element during loading causes the normal stress to be higher during that specific step. Friction coefficients and displacement amplitude do not influence the compressive normal stress during loading. Meanwhile, a visible effect of friction coefficient and displacement amount can be noticed during the scratching as normal stress reduces during that particular period. This is mainly due to the occurrence of the tensile normal stress during scratching. Such effect can be noticed significantly for higher amounts of friction coefficient and displacement amplitude.

Normal stress is based on compressive stress. Higher the compressive stress results in high normal stress. During scratching step, the tensile stress occurs together with compressive stress. The tensile stress reduces compressive stress, thus resulting in a drop in normal stress. In addition, the response of friction coefficient is more obvious compared to displacement amplitude due to higher surface traction. Furthermore, the normal stress occurring on Super CMV material is higher for all the steps and conditions because of the high ultimate strength compared to Ti-6Al-4V.

\section{Influence of Friction Coefficient and Displacement Amplitude on Shear Stress Distributions}

Figure 6 shows shear stress history using different coefficients of frictions for Super CMV and Ti-6Al-4V materials. The trend of the graph shows that shear stress is similar for the entire friction coefficient during loading according to the material. The shear stress is higher during earlier stage of the scratching for friction coefficient of 0.3 and slowly decreases; while for the 0.6 and 0.9 , the shear stress is higher at the final stage of the scratching. The shear stress distribution is almost similar for friction coefficient of 0.6 and 0.9 according to the material. The shear stress acting on Super CMV is higher than Ti-6Al-4V. The higher coefficient of friction increases the shear stress, where lower shear stress is noted for 0.3 friction coefficient compared to 0.6 and 0.9 , particularly during scratching. The shear stress of the substrate is reduced gradually during unloading, but higher friction coefficient causes more fluctuations for both materials.

Figure 7 shows shear stress history using different scratching displacement amplitudes for Super CMV and Ti-6Al-4V materials. The trend of the graph displays that shear stress is similar for all the displacement amplitudes during loading according to the materials. The shear stress is higher at the initial stage of the scratching and slowly decreases. The reduction in shear stress during scratching is very significant for higher displacement amplitude for both materials. Besides that, the shear stress acting on Super CMV is higher than Ti-6Al-4V. The higher scratching displacement amplitude increases the shear stress, where lower shear stress is recorded for $0.05 \mathrm{~mm}$ displacement compared 
to $0.1 \mathrm{~mm}$ and $0.2 \mathrm{~mm}$, mainly during scratching. The shear stress of substrate is reduced progressively during unloading.

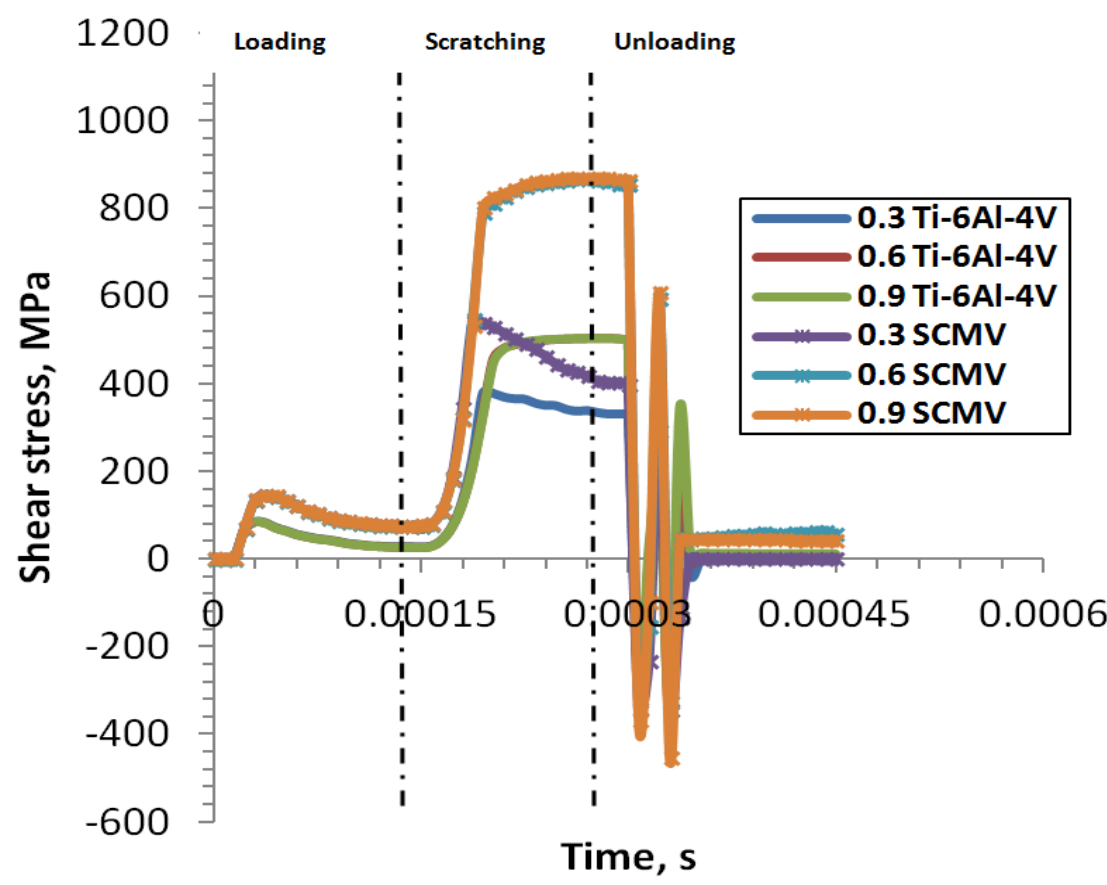

Figure 6. The shear stress history for different friction coefficients.

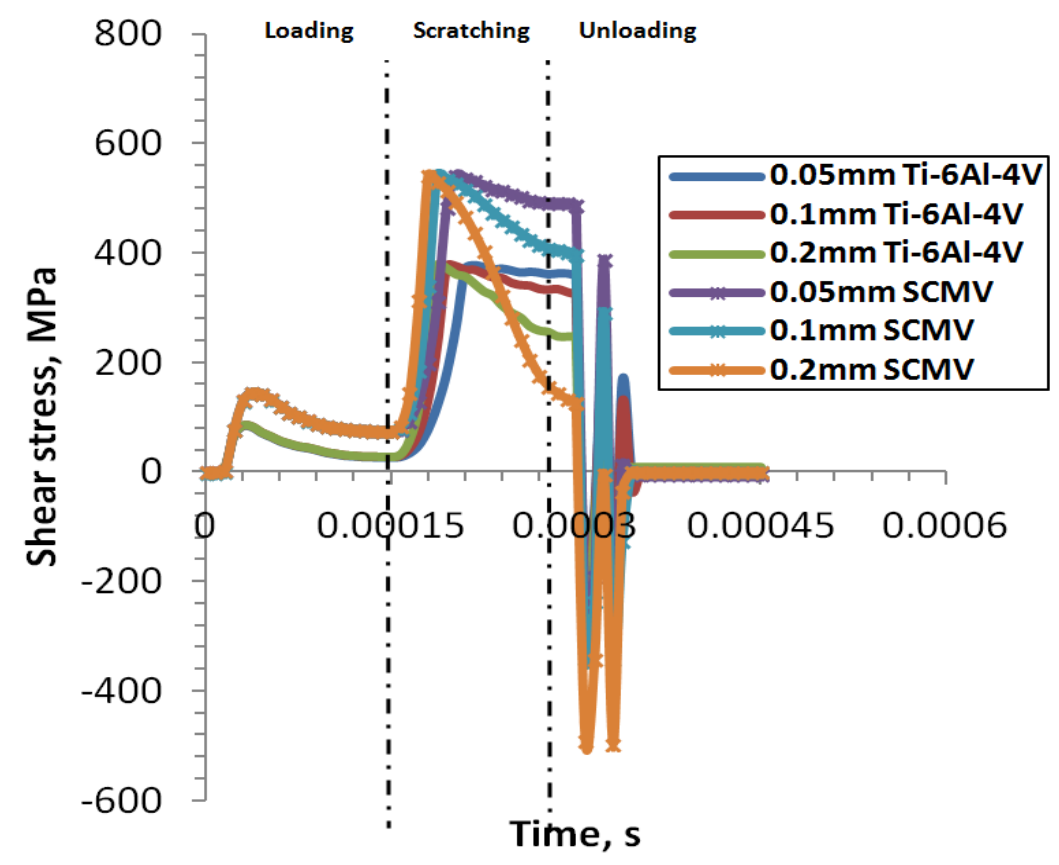

Figure 7. The shear stress history for different displacement amplitudes.

The shear stress is also influenced by the effect of the friction coefficient and scratching displacement amplitude for both materials. There are no significant changes on shear stress due to alteration of analysed variables. The shear stress distribution is 
mainly affected during scratching as element stretched during that particular step. The higher friction induced and causes shear traction due to higher friction coefficient which results in significant shear stress. Meanwhile, higher displacement amplitude reduces the shear stress as the initial shear traction passed to the following elements of the subsurface parallel to the displacement directions and motion. Higher friction coefficient causes more friction on the substrate when the indenter is scratching on it. Higher friction results in shear traction on the surface and causes the value of the shear stress to become more significant.

\section{Influence of Friction Coefficient and Displacement Amplitude on Von Mises Stress Distributions}

Figure 8 illustrates von Mises stress history of different friction coefficients for Super CMV and Ti-6Al-4V materials. The trend of the graph shows that Von Mises stress is increasing simultaneously for all the friction coefficients during loading according to the material. The maximum stress is recorded during scratching for all the friction cases. Higher friction coefficient displays higher von Mises stress while lower stress is noted for friction coefficient of 0.3. Meanwhile, only an insignificant difference is noted between 0.6 and 0.9 respectively. The von Mises stress acting on Super CMV is higher than Ti-6Al-4V. The unloading process causes gradual drop in stress, where residual stress can be noticed.

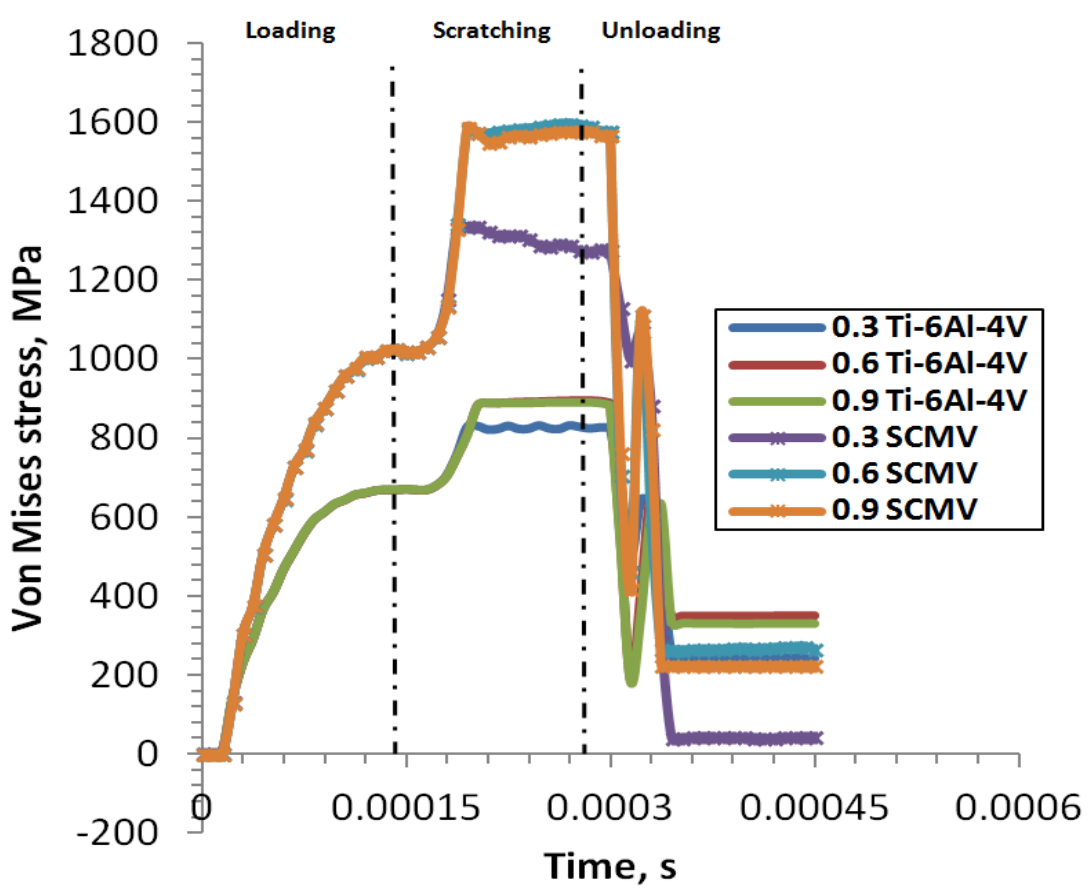

Figure 8. The von Mises stress history for different friction coefficients.

Figure 9 illustrates von Mises stress history of different scratching displacement amplitudes for Super CMV and Ti-6Al-4V materials. The trend of the graph shows that von Mises stress is increasing concurrently for all displacement amplitudes during loading stage according to the materials. The maximum stress is predicted during scratching for all the displacement cases. Higher displacement amplitude exhibits higher von Mises stress especially at the earlier stage of scratching. In addition, the reduction in von Mises 
stress during scratching is visible in Super CMV material compared to Ti-6Al-4V. The predicted von Mises stress acting on Super CMV is greater than Ti-6Al-4V. The unloading process causes sudden drop in stress, where residual stress can be detected.

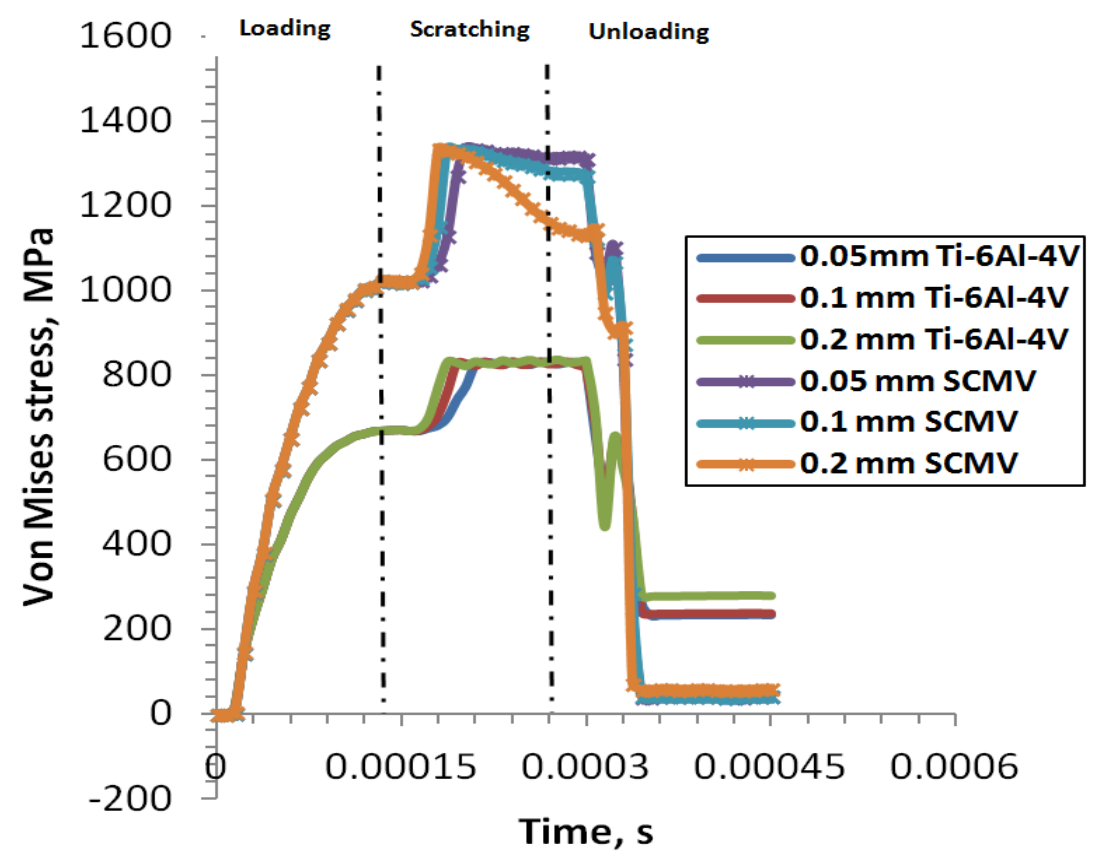

Figure 9. The von Mises stress history for different displacement amplitudes.

The effect of the friction coefficient and scratching displacement amplitude can be seen in the von Mises stress graphs. The von Mises stress increases constantly during loading for all conditions as the result of the force acts on the material. The maximum stress is achieved during scratching stage as the effect of frictional force increases the stress for higher friction coefficients. Meanwhile, higher displacement amplitudes show that stress is reduced as the load propagates from one place to another; thus, stress concentration is distributed along with the displacement, especially in Super CMV material. The higher yield stress and ultimate strength of Super CMV properties cause this kind of effect where the effect of tensile stress is more significant in Super CMV material compared to Ti-6Al-4V. The higher yield stress and ultimate strength of Super CMV records higher von Mises stress compared to Ti-6Al-4V.

\section{Influence of Friction Coefficient and Displacement Amplitude on Von Mises Residual Stress Distributions}

Figure 10 shows von Mises residual stress history using different coefficients of frictions for Super CMV and Ti-6Al-4V materials. The residual stress can be noticed at the complete unloading. Super CMV material displays lower residual stress compared to Ti6Al-4V. The residual stress recorded for Super CMV with friction coefficient of 0.3, 0.6 and 0.9 are $42.189 \mathrm{MPa}, 265.989 \mathrm{MPa}$ and $224.334 \mathrm{MPa}$, while for Ti-6Al-4V are 240.878 MPa, 349.275 MPa and 328.695 MPa respectively, as shown in Figure 8. Higher residual stress is predicted for friction coefficient of 0.6 for both materials.

Figure 11 shows von Mises residual stress history using different scratching displacement amplitudes for Super CMV and Ti-6Al-4V materials respectively. The residual stress can be observed after complete unloading. Super CMV material 
demonstrates lower residual stress compared to Ti-6Al-4V. The residual stress recorded for Super CMV with scratching displacement amplitudes of $0.05 \mathrm{~mm}, 0.1 \mathrm{~mm}$ and 0.2 $\mathrm{mm}$ are 42.634 MPa, 44.380 MPa and 58.229 MPa, while for Ti-6Al-4V are 233.005 $\mathrm{MPa}, 236.682 \mathrm{MPa}$ and 278.541 MPa respectively as shown in Figure 12. Higher residual stress is predicted for higher scratching displacement amplitudes for both materials.

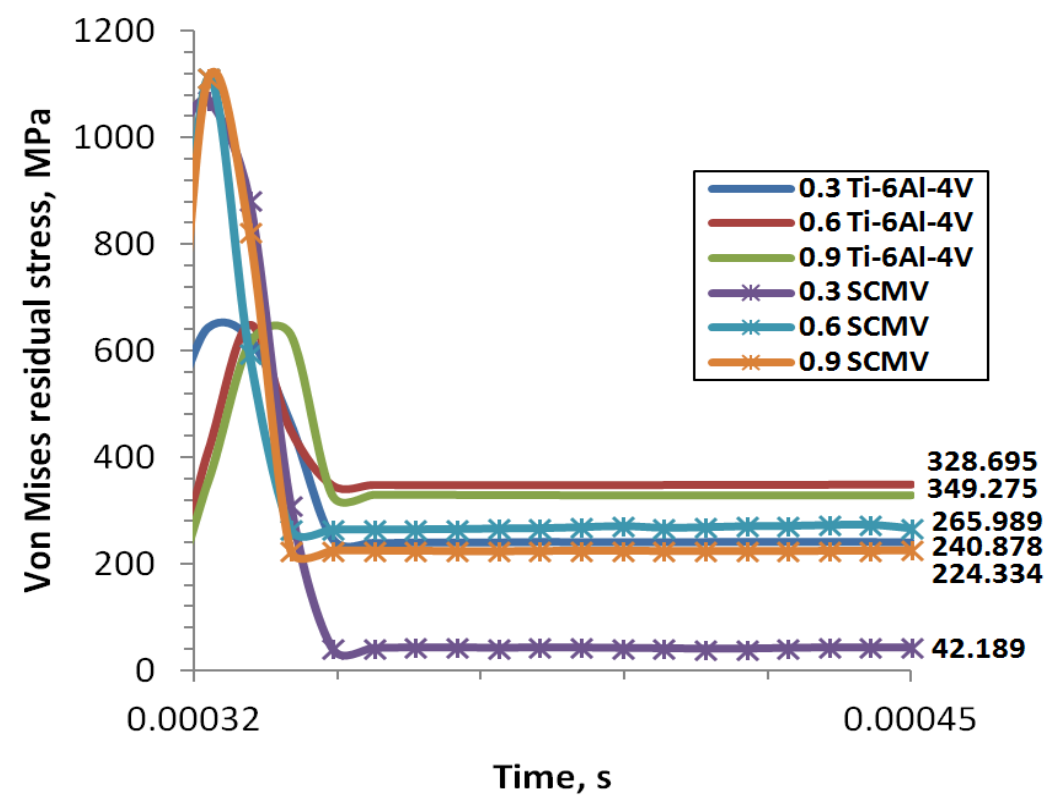

Figure 10. The von Mises residual stress history for different friction coefficients.

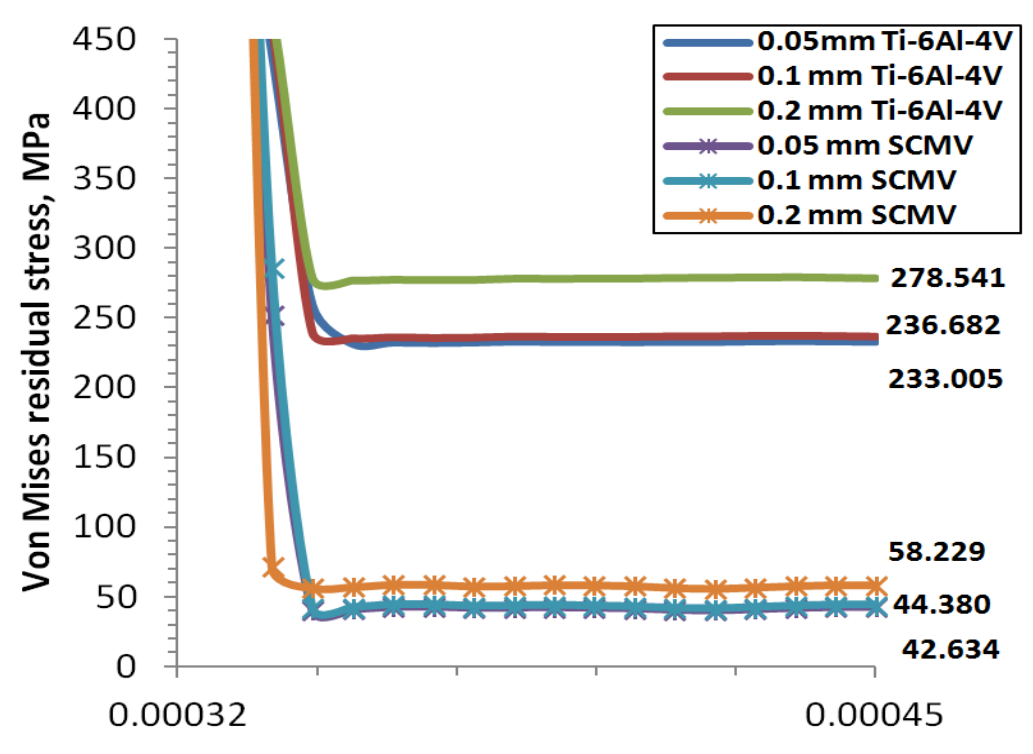

Time, s

Figure 11. The Von Mises residual stress history for different displacement amplitudes. 
The von Mises residual stress is also affected by the friction coefficient and scratching displacement amplitude. The residual stress is noticeable after the complete unloading. The residual stress in both materials is higher for friction coefficient of 0.6 because the effect of the frictional force is significant at the subsurface of the substrate, while for 0.9 friction coefficient, the effect is mainly on the surface because of its higher surface traction force. In addition, the residual stress is greater for higher displacement amplitude as the stress is applied on extended contact length compared to lower displacement contact length. Thus, higher remaining stress is captured for $0.2 \mathrm{~mm}$ of displacement. The different materials properties lead to lower residual stress in Super CMV than Ti-6Al-4V alloys.

\section{CONCLUSIONS}

The main aim of the present study is to examine the influence of friction coefficient and scratching displacement amplitude on the von Mises residual stress along with normal and shear stress distributions for Super CMV and Ti-6Al-4V materials using cylinder-onflat contact configuration FE model. FE model using both materials gives a better agreement with Hertzian maximum contact pressure and contact half-width length where less than $5 \%$ of error is recorded. It is found that the effect of higher friction coefficient and displacement amount can be noticeable during the scratching where normal stress reduces due to tensile normal stress. The higher friction coefficient causes shear traction and results in significant shear stress, while initial shear traction is reduced due to higher displacement amplitude as the displacement progressed from one element to another. The higher residual stress is recorded for friction coefficient of 0.6 and $0.2 \mathrm{~mm}$ scratching displacement amplitude. Super CMV material with friction coefficient of 0.3 and scratching displacement amplitude of $0.10 \mathrm{~mm}$ is recommended to be used in contact engineering applications due to its minimum possibility of fatigue.

\section{ACKNOWLEDGEMENTS}

The authors would like to convey their appreciation for the financial support provided by the Ministry of Education Malaysia and Universiti Tun Hussein Onn Malaysia. This research is supported by the Research Acculturation Collaborative Effort (RACE), Vot. No. 1441.

\section{REFERENCES}

[1] Liang SY, Su JC. Residual Stress Modeling in Orthogonal Machining. CIRP Annals - Manufacturing Technology. 2007;56:65-8.

[2] Micro-Measurements V. Measurement of residual stresses by the hole drilling strain gage method. Tech Note TN-503-6; 2005.

[3] Yang X, Liu CR. A new stress-based model of friction behavior in machining and its significant impact on residual stresses computed by finite element method. International Journal of Mechanical Sciences. 2002;44:703-23.

[4] Matsumoto Y, Magda D, Hoeppner D, Kim TY. Effect of machining processes on the fatigue strength of hardened AISI 4340 steel. Journal of Manufacturing Science and Engineering. 1991;113:154-9.

[5] Liu CR, Mittal S. Optimal pre-stressing the surface of a component by superfinish hard turning for maximum fatigue life in rolling contact. Wear. 1998;219:128-40. 
[6] Yang X, Liu CR, Grandt A. An experimental study on fatigue life variance, residual stress variance, and their correlation of face-turned and ground Ti 6Al4V samples. Journal of manufacturing science and engineering. 2002;124:809-19.

[7] Jeffrey K, Tarlochan F, Rahman M. Residual strength of chop strand mats glass fiber/epoxy composite structures: effect of temperature and water absorption. International Journal of Automotive and Mechanical Engineering. 2011;4:504-19.

[8] Abdul Majid M, Daud R, Afendi M, Amin N, Cheng E, Gibson A. Stress-strain response modelling of glass fibre reinforced epoxy composite pipes under multiaxial loadings. Journal of Mechanical Engineering and Sciences. 2014;6:916-28.

[9] Kadirgama K, Rahman M, Ismail A, Bakar R. Finite element analysis of Hastelloy $\mathrm{C}-22 \mathrm{HS}$ in end milling. Journal of Mechanical Engineering and Sciences. 2011;1:37-46.

[10] Khan MAR, Rahman M, Kadirgama K, Maleque M, Ishak M. Prediction of surface roughness of Ti-6Al-4V in electrical discharge machining: A regression model. Journal of Mechanical Engineering and Sciences. 2011;1:16-24.

[11] Ford T. Mainshafts for the Trent. Aircraft Engineering and Aerospace Technology. 1997;69:555-60.

[12] Hyde TR. Development of a representative specimen for fretting fatigue of spline joint couplings: Nottingham University; 2002.

[13] Mohd Tobi AL, Ding J, Bandak G, Leen SB, Shipway PH. A study on the interaction between fretting wear and cyclic plasticity for Ti-6Al-4V. Wear. 2009;267:270-82.

[14] McColl IR, Ding J, Leen SB. Finite element simulation and experimental validation of fretting wear. Wear. 2004;256:1114-27.

[15] Khan MAR, Rahman MM, Kadirgama K, Maleque MA, Ishak M. Prediction of Surface Roughness of Ti-6Al-4V in Electrical Discharge Machining: A Regression Model. Journal of Mechanical Engineering and Sciences. 2011;1:1624.

[16] Singh R, Singh B. Comparison of Cryo-treatment Effect on Machining Characteristics of Titanium in Electric Discharge Machining. International Journal of Automotive and Mechanical Engineering. 2011;3:239-48.

[17] Khan MAR, Rahman MM, Kadirgama K. Electrode Wear Rate of Graphite Electrodes during Electrical Discharge Machining Processes on Titanium Alloy Ti-5Al-2.5Sn. International Journal of Automotive and Mechanical Engineering. 2014;9:1792-.

[18] Ali N, Mustapa MS, Ghazali MI, Sujitno T, Ridha M. Fatigue Life Prediction of Commercially Pure Titanium after Nitrogen Ion Implantation. International Journal of Automotive and Mechanical Engineering. 2013;7:1005-13.

[19] Laukkanen A, Holmberg K, Koskinen J, Ronkainen H, Wallin K, Varjus S. Tribological contact analysis of a rigid ball sliding on a hard coated surface, Part III: Fracture toughness calculation and influence of residual stresses. Surface and Coatings Technology. 2006;200:3824-44.

[20] Kim JW, Lee YZ. The residual stresses on lubricated sliding surfaces during break-in and up to scuffing. Wear. 2001;251:985-9.

[21] Borst RD, Crisfield MA, Remmers JJC, Verhoosel CV. Non-linear finite element analysis of solids and structures.Wiley, 2012.

[22] Wriggers P, Zavarise G. Computational contact mechanics. Encyclopedia of computational mechanics. 2004. 
[23] Liu CR, Guo YB. Finite element analysis of the effect of sequential cuts and toolchip friction on residual stresses in a machined layer. International Journal of Mechanical Sciences. 2000;42:1069-86.

[24] Foletti S, Desimone HJ. A semi-analytical approach for two-dimensional rolling/sliding contact with applications to shakedown analysis. Wear. 2007;262:850-7.

[25] Linz M, Winkelmann H, Hradil K, Badisch E, Mücklich F. Directional development of residual stress and surface fatigue during sliding contact. Engineering Failure Analysis. 2013;35:678-85.

[26] Hibbitt H, Karlsson B, Sorensen P. ABAQUS theory manual, version 6.3. Pawtucket, Rhode Island, USA. 2006.

[27] Nagentrau M, Siswanto WA, Tobi M, Latif A. Investigation on the effect of linear kinematic hardening model on plasticity prediction of reciprocating sliding contact. 2014.

[28] Leen S, Richardson I, McColl I, Williams E, Hyde T. Macroscopic fretting variables in a splined coupling under combined torque and axial load. The Journal of Strain Analysis for Engineering Design. 2001;36:481-97.

[29] Benedetti M, Fontanari V. The effect of bi-modal and lamellar microstructures of Ti-6Al-4V on the behaviour of fatigue cracks emanating from edge-notches. Fatigue \& fracture of engineering materials \& structures. 2004;27:1073-89.

[30] Matos R, Vargas J, Laursen T, Saboya F. Optimization study and heat transfer comparison of staggered circular and elliptic tubes in forced convection. International Journal of Heat and Mass Transfer. 2001;44:3953-61.

[31] Johnson KL, Johnson KL. Contact mechanics: Cambridge university press; 1987. 